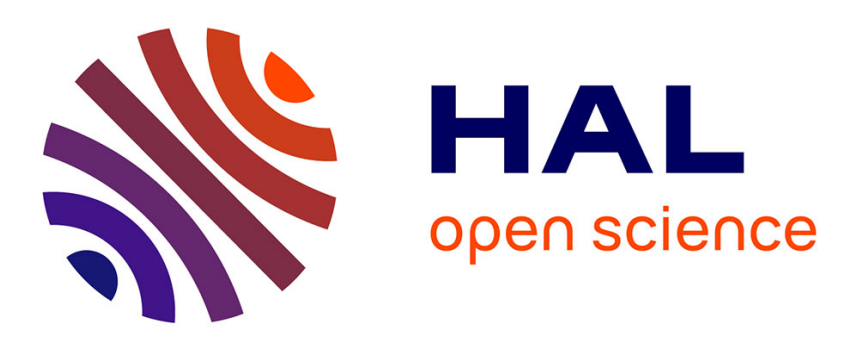

\title{
Electronic and crystallographic structures of silver adsorbed on silicon (111)
}

\author{
J. Derrien, G. Le Lay, F. Salvan
}

\section{To cite this version:}

J. Derrien, G. Le Lay, F. Salvan. Electronic and crystallographic structures of silver adsorbed on silicon (111). Journal de Physique Lettres, 1978, 39 (16), pp.287-290. 10.1051/jphyslet:019780039016028700 . jpa-00231499

\section{HAL Id: jpa-00231499 https://hal.science/jpa-00231499}

Submitted on 1 Jan 1978

HAL is a multi-disciplinary open access archive for the deposit and dissemination of scientific research documents, whether they are published or not. The documents may come from teaching and research institutions in France or abroad, or from public or private research centers.
L'archive ouverte pluridisciplinaire HAL, est destinée au dépôt et à la diffusion de documents scientifiques de niveau recherche, publiés ou non, émanant des établissements d'enseignement et de recherche français ou étrangers, des laboratoires publics ou privés. 


\author{
Classification \\ Physics Abstracts \\ $73.20-61.14 \mathrm{Hg}-79.20 \mathrm{~m}$
}

\title{
ELECTRONIC AND CRYSTALLOGRAPHIC STRUCTURES OF SILVER ADSORBED ON SILICON (111)*
}

\author{
J. DERRIEN, G. LE LAY \\ Centre de Recherche des Mécanismes de la Croissance Cristalline, CNRS. \\ Universités Aix-Marseille II et III. Centres de Luminy et de St-Jérôme, \\ 13288 Marseille Cedex 2, France \\ and F. SALVAN \\ Groupe de Physique des Etats Condensés, ERA 373 CNRS. U.E.R. Scientifique de Luminy. \\ Université Aix-Marseille II, 13288 Marseille Cedex 2, France \\ (Reçu le 24 avril 1978, révisé le 27 juin 1978, accepté le 4 juillet 1978)

\begin{abstract}
Résumé. - On montre que la méthode des pertes d'énergie d'électrons lents est très sensible au mécanisme de croissance des atomes sur un substrat solide, sous ultra-vide. Appliquée à l'interface argent-silicium, cette méthode révèle des spectres des pertes d'énergie différents selon que l'argent forme un film bidimensionnel continu (basse température) ou un film discontinu de cristallites tridimensionnelles (haute température).
\end{abstract}

\begin{abstract}
We show, in this letter, direct relations between the electronic properties of the
\end{abstract} \\ $\mathrm{Ag} / \mathrm{Si}(111)$ system as investigated by low energy electron loss spectroscopy (ELS), and the silver \\ growth process as monitored with electron diffraction (LEED, RHEED and TEM) and Auger \\ electron spectroscopy (AES). At room temperature, where two-dimensional (2D) epitaxial layers \\ are formed, the ELS spectra reveal almost bulk-silver-like transitions for metal overlayer coverage \\ as low as $\theta \sim 3$. At high temperatures $\left(>200^{\circ} \mathrm{C}\right.$ ), where three-dimensional (3D) growth occurs \\ after completion of a first ordered layer, the ELS spectra are similar to those of bulk-silver, but \\ only for high coverage $(\theta \gtrsim 30)$. We discuss also the physical origin of the Ag ELS peaks observed \\ in thin films.
}

The formation of the Schottky barriers (SB) in metal semiconductor systems is of scientific and practical interest. In a recent paper, Rowe et al. [1] have published results on the (SB) formation of $\mathrm{Al}$, $\mathrm{Ga}$ and In deposited on $\mathrm{Si}(111)$. There have been some questions raised about the metal overlayer homogeneity and its relation to the ELS spectra. In this letter, we deal with this problem, using the ELS technique, widely employed now in solid surface investigations $[2,3,4]$.

We will show unambigously that differences in ELS data for the same surface coverages are related to different growth mechanisms. Thus, this provides new experimental verification of the conclusions published by Le Lay et al. [5] relating to the early stages of $\mathrm{Ag}$ growth on the $\mathrm{Si}(111)$ surface ; namely,

(*) I his work is, in part, supported by DGRST under contract 77.7.1651. that at room temperature and below $200{ }^{\circ} \mathrm{C}$ two dimensional (2D) epitaxial layers are formed, while at higher temperatures $\left(>200^{\circ} \mathrm{C}\right)$ three dimensional (3D) clusters develop over a first adsorbed Ag layer. An additional significant feature of the results reported here is the strong similarity of the ELS data of a few $\mathrm{Ag}$ layers and of bulk Ag. The latter will be examined in the light of both theoretical calculations of electronic density of states (EDOS) of a few $\mathrm{Cu}$ layers $[6,7,8]$ and of recent photoemission data $[8,9]$.

All experiments were carried out in a multiple technique UHV chamber described elsewhere [10]. The Si sample was cleaved in situ $(2 \times 1$ LEED pattern) and annealed to obtain a LEED $7 \times 7$ diagram. Silver was deposited by means of a Knudsen cell located in an independent chamber, with its own pumping set up, and connected to the UHV chamber by a diaphragmed junction. An externally operated shutter controlled the metal deposition 
whose thickness was calibrated by several techniques (quartz oscillator, AES and mass spectrometry). A monolayer could be obtained in ten minutes $(\theta=1$ when there is one $\mathrm{Ag}$ atom per one $\mathrm{Si}$ atom on the $\mathrm{Si}(111)$ surface). The ELS spectra were recorded at each stage of the Ag deposition (every $\theta=0.1$ up to $\theta \sim 30$ ). The incident electron energy was between $70 \mathrm{eV}$ and $300 \mathrm{eV}$ and the back scattered electrons were analysed by means of a cylindrical mirror analyser in the negative second derivative mode $-\frac{\mathrm{d}^{2} N}{\mathrm{~d} E^{2}}$ of the reflected electron energy distribution. The energy resolution was about $0.8 \mathrm{eV}$.

At temperatures below $\sim 200{ }^{\circ} \mathrm{C}, \mathrm{Ag}$ atoms form a first continuous layer giving a blurred $\sqrt{3}$ LEED or RHEED pattern for $\theta=2 / 3$. This first adsorbed layer does not correspond to a close packed (111) plane of silver on $\mathrm{Si}(111)$. If more than $\theta=2 / 3$ of $\mathrm{Ag}$ atoms are deposited, they grow on the top of this first layer in a (111) 2D layer-by-layer fashion as observed by AES [5]. The atomic density of these next layers corresponds now to a close packed (111) plane of silver. Some characteristic ELS spectra of this Frank-van der Merwe growth mechanism are shown in figure 1. All the loss peaks observed

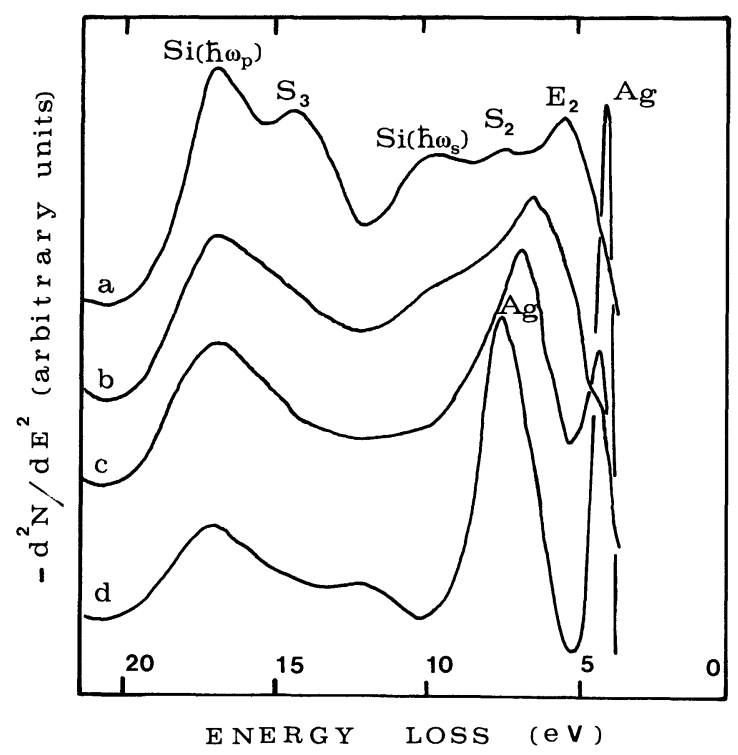

Fig. 1. - Electron loss spectra of $\mathrm{Ag} / \mathrm{Si}(111)$ at room temperature. The primary electron energy $E_{\mathrm{p}}$ is $70 \mathrm{eV}: a$ ) clean $\mathrm{Si}(111)$ $7 \times 7$ surface; b) $\theta=1 / 3 ; c) 0=2 / 3$. A blurred $\sqrt{3}$ layer is observed here with LEED; $d$ ) $\theta=2.5$. Note that for this thin film ( $2 \mathrm{Ag}$ layers on $\mathrm{Si}$ ), the ELS spectrum is practically that of bulk-silver.

on the spectrum of the clean Si $7 \times 7$ surface have already been identified $[1,2]$. We use here the same notations as these authors and attribute, in the same manner, the $S_{3}(\sim 14.5 \mathrm{eV})$ and the $S_{2}(\sim 7.7 \mathrm{eV})$ peaks to electronic transitions involving surface states, the $\mathrm{Si}\left(\hbar \omega_{\mathrm{p}} ;\right.$ to the bulk silicon plasmon $(\sim 17.2 \mathrm{eV})$, the $\mathrm{Si}\left(\hbar \omega_{\mathrm{s}}\right)$ to the surface plasmon $(\sim 10.7 \mathrm{eV})$ and the $E_{2}$ peak $(\sim 5.5 \mathrm{eV})$ to a bulk silicon interband transition (Fig. 1a). When $\mathrm{Ag}$ atoms are deposited on the surface, all the clean $\mathrm{Si}$ surface peaks disappear quickly (Fig. 1b-d), while the bulk peak intensity slowly decreases with $\mathrm{Ag}$ coverage. Note the apparent drastic decrease of the $E_{2}$ peak, due to the onset of neighbouring Ag peaks $(\sim 7.1 \mathrm{eV}$ and $\sim 4.6 \mathrm{eV})$. These two $\mathrm{Ag}$ induced peaks appear at very low coverage (Fig. $1 b-c$ ). They are rather broad in the first monolayer range. At completion of the second close packed $\mathrm{Ag}$ layer on the top of the first $\sqrt{3}$ layer (Fig. 1d), they narrow and shift to the bulk-silver-like excitations $(\sim 7.5 \mathrm{eV}$ and $\sim 4 \mathrm{eV}$ ) [11-14]. After the second layer, modifications in intensity rather than in shape occur for these two peaks.

At high temperatures $\left(>200{ }^{\circ} \mathrm{C}\right)$, the situation is quite different. In this case, ordered adsorption occurs initially with a $3 \times 1$ LEED pattern at $\theta=1 / 3$, followed, when the coverage increases, by a sharp $\sqrt{3} \times \sqrt{3}-R\left(30^{\circ}\right)$ pattern at $\theta=2 / 3$. After this first ordered layer, 3D clusters of $\mathrm{Ag}$ in parallel epitaxy $(\langle 111\rangle \mathrm{Ag} / /\langle 111\rangle \mathrm{Si},\langle 1 \overline{1} 0\rangle \mathrm{Ag} / /\langle 1 \overline{1} 0\rangle \mathrm{Si})$ develop according to the Stranski-Krastanov growth process. This conclusion has been obtained with RHEED, AES and electron microscopy of surface replicas [5, 10]. The corresponding ELS spectra are shown in figure 2 . Of course, no noticeable difference with the room temperature spectra (Fig. 2a-c), is observed during the first monolayer growth, the

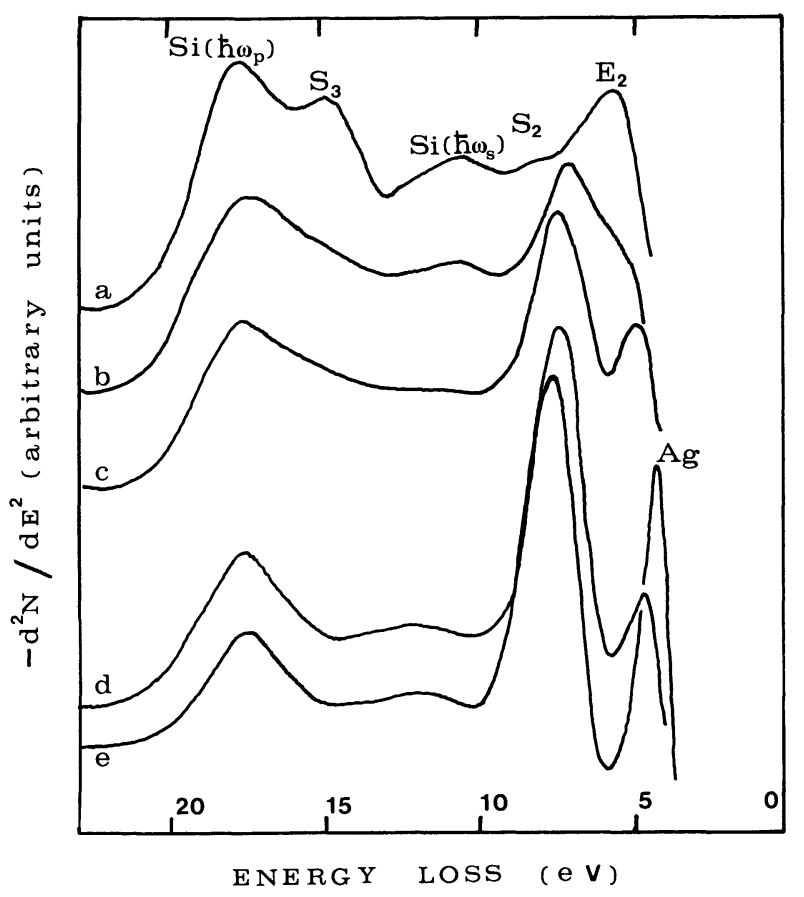

Fig. 2. - Electron loss spectra of $\mathrm{Ag} / \mathrm{Si}(111)$ at $400^{\circ} \mathrm{C} . E_{\mathrm{p}}=70 \mathrm{eV}$. a) Clean $\operatorname{Si}(111) 7 \times 7$ surface; $b) \theta=1 / 3$. A $3 \times 1$ LEED pattern is observed here ; c) $\theta=2 / 3$. A sharp $\sqrt{3}$ layer is observed here with LEED; $d$ ) $\theta=10$. 3D clusters grow on top of the $\sqrt{3}$ layer. The ELS spectrum looks the same as that for $\theta=2 / 3$; e) $\theta \sim 30$. The ELS spectrum begins to evolve to that of bulksilver. 
growth mode being essentially the same, and the same $\sqrt{3}$ layer is observed at $\theta=2 / 3$. But for higher $\theta$, for which we now observe $3 \mathrm{D}$ clusters instead of a 2D film, the ELS spectra remain unchanged [15] (Fig. $2 c-d$ ). In order to obtain a spectrum nearly similar to that of bulk-silver (Fig. $2 e$ ), an adsorption of $\theta \sim 30$ is required [15].

The ELS spectra of both the 2D thin silver film and the $3 \mathrm{D}$ clusters do not show significant changes with incident electron energy (between 70 and $300 \mathrm{eV}$ ). By increasing this energy, one only favours the bulk transition peak intensities compared to the surface transition peak intensities as already mentioned [3]. The Auger lines were also checked during Ag deposition. The Si Auger line intensity (LVV - $92 \mathrm{eV}$ ) decreases while that of the Ag doublet $(\mathrm{MNN} \sim 355 \mathrm{eV})$ increases. However, the shape of both $\mathrm{Si}$ and $\mathrm{Ag}$ Auger lines do not change for the whole investigated coverage range $(0<\theta<30)$. This fact suggests that silver does not react drastically with $\mathrm{Si}$. This may be a reason why for this interface, only a superposition of ELS features from the semiconductor and the metal is apparent. No peak related to a coupled interface plasmon mode is observed as in the $\mathrm{Al} / \mathrm{CdS}$ system [16]. This result is similar to recent data on $\mathrm{Ag} / \mathrm{CdS}$ [17].

An experiment which summarizes the essential points of the relation between the crystallographic structures and the ELS spectra discussed above is described in figure 3. A smooth 2D Ag film, adsorbed at room temperature (say $\theta \sim 3$ ) is annealed until

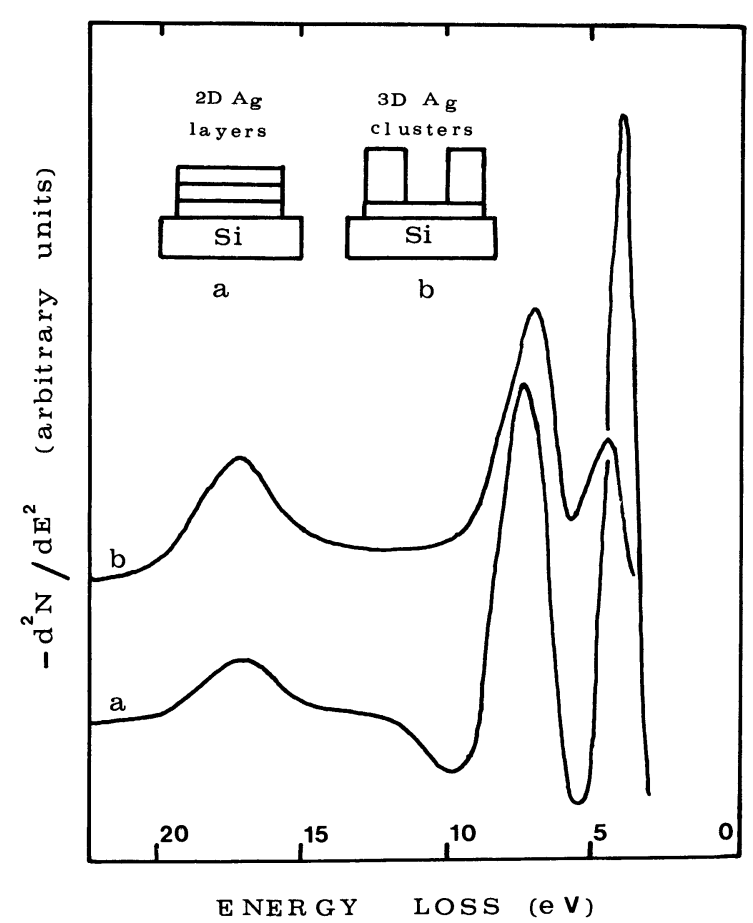

FIG. 3. - Electron loss spectra of the same Ag average thickness $(\theta \sim 3)$, but growing in two different modes : a) thin Ag smooth film adsorbed first at room temperature (2D growth mechanism); b) the same film is annealed at $400^{\circ} \mathrm{C}$ where it transforms into $3 \mathrm{D}$ clusters. $400^{\circ} \mathrm{C}$, where no desorption occurs, for a few minutes. The smooth film transforms into $3 \mathrm{D}$ clusters on top of the $\sqrt{3}$ layer. In exactly the same way, the initial ELS spectrum of the smooth film (i.e. a bulk-Ag-like spectrum, figure $3 a$ ) evolves into the ELS spectrum of the first $\sqrt{3}$ layer (Fig. 3b) [15].

We wish now to discuss the two ELS Ag peaks. High energy electron loss data in thin Ag films have been reported [11-14] which are in good agreement with the optical determination of the real part $\varepsilon_{1}$ and the imaginary part $\varepsilon_{2}$ of the complex dielectric constant $\varepsilon$ [18] and band structures of noble metals [19]. The loss peaks are displayed as maxima in the $\operatorname{Im}(-1 / \varepsilon)$ function versus energy. In the range $0-10 \mathrm{eV}$, two main peaks at $\sim 4.0 \mathrm{eV}$ and $\sim 7.5 \mathrm{eV}$ are observed. They are explained in the following manner [14] : the bulk $\mathrm{Ag} \mathrm{d}$ band extends from $4 \mathrm{eV}$ to $7.5 \mathrm{eV}$ below the Fermi level, $E_{\mathrm{F}}$. Strong transitions from this d band to $E_{\mathrm{F}}$ or to unoccupied parts of the $5 \mathrm{sp}$ band give rise to a rather broad peak observed on the $\varepsilon_{2}$ versus energy curve. This $\varepsilon_{2}$ peak splits the free electron plasmon of silver $(\sim 9 \mathrm{eV}$, predicted with one 5 s electron per silver atom) into two hybrid plasmons which account for the two loss peaks observed at $4 \mathrm{eV}$ and $7.5 \mathrm{eV}$.

Looking now at our ELS data in the first monolayer range (Fig. 1), it seems obvious that the two peaks observed at $4.6 \mathrm{eV}$ and $7.1 \mathrm{eV}$ can be related to transitions coming from the $\mathrm{d}$ band development which has not yet shown all the bulk $d$ band features. This monolayer $d$ band should be narrower than the bulk band and should lie at lower energies below $E_{\mathrm{F}}$. This fact would explain the energy position of two observed peaks for the first $\sqrt{3}$ layer $(4.6 \mathrm{eV}$ and $7.1 \mathrm{eV})$. If a second closed packed $\operatorname{Ag}(111)$ layer is built up over the first layer, the $d$ band of this two layers film displays now practically all the bulk features, i.e. it broadens slightly and its upper edge shifts towards $E_{\mathrm{F}}$. This can explain the evolution of the $4.6 \mathrm{eV}$ to the $4 \mathrm{eV}$ (Fig. $1 d$ ).

All the arguments, given above, on the shift of the Ag band during growth, are suggested by recent calculations of Abbati et al. [8] on the $\mathrm{Cu}$ d-band shifts. Nevertheless, the shift on the $7.1 \mathrm{eV}$ to $7.5 \mathrm{eV}$ (Fig. 1d), cannot be easily explained on the basis of their results. We believe that this evolution is caused by the increase of the 5 s electron density, from the second layer, which increases the free plasmon energy which in turn shifts the second hybrid plasmon $7.1 \mathrm{eV}$ to $7.5 \mathrm{eV}$.

Our results for a two continuous layer film is to be related to recent photoemission data on very thin metallic films [8, 9] and to their EDOS theoretical calculations [7, 8]. The work of Gay et al. [7] shows that a film of $3 \mathrm{Cu}$ layers already displays the $\mathrm{Cu}$ bulk EDOS. This is due both to the localized nature of the $\mathrm{d}$ orbitals and to the identity of the atomic environments in the second layer and in the bulk material. We expect that these arguments should 
apply for silver which has the same outer electronic configuration.

It is to be noted that similar results are obtained on the same system by Wehking et al. [9]. Their UV photoemission measurements showed that already at a monolayer the $\mathrm{d}$ band developed and split in several peaks with increasing thickness.

We conclude with a discussion of the influence of the growth mechanisms (2D and 3D) on the behaviour of the hybrid plasmon resonance $(4.0 \mathrm{eV}$ peak $)$. Due to the peculiar variation of $\varepsilon_{1}(\omega)$ in silver [11], the surface and bulk plasmon occur at nearly the same energy (respectively $3.6 \mathrm{eV}$ and $3.8 \mathrm{eV}$ ) [13]. Our limited resolution $(0.8 \mathrm{eV})$ does not allow us to distinguish these two plasmon peaks. Nevertheless. for $2 \mathrm{D}$ smooth films. the $4.0 \mathrm{eV}$ peak has the overall features of a surface plasmon. First, it is very sensitive to the structure of the Ag overlayers (Fig. 3). Second, it appears suddenly after the formation of a film of two monolayers. Moreover, for films of 3D clusters, even at $\theta=10$, where there is a sufficient thickness to show bulk $\mathrm{Ag}$ features, the surface is so poorly defined that a collective surface oscillation is very difficult $[20,21]$ and so, the plasmon contribution to the $4.0 \mathrm{eV}$ peak would not be apparent (Fig. $2 d$ ). This may explain its rather slow evolution with thickness (Fig. 2d-e).

We are indebted to Pr. J. G. Dash and to Dr. B. Goldstein for valuable discussions and helpful readings of the manuscript, and to $M$. Manneville for skillful technical assistance.

\section{References}

[1] Rowe, J. E., Margaritondo, G. and Christman, S. B.. Phys. Rev. B 15 (1977) 2195.

[2] Rowe, J. E. and IвaCh, H., Phys. Rev. Lett. 31 (1973) 102.

[3] Ludeke, R. and Esaki, L., Phys. Rev. Lett. 33 (1974) 653.

[4] Derrien, J., Arnaud d'Avitaya, F. and Bienfait, M., Solid. State Commun. 20 (1976) 557.

[5] Le Lay, G., Manneville, M. and Kern, R., Surf. Sci. 72 (1978) 405

[6] Sohn, K. S., Dempsey, D. G., Kleinman, L. and CaruTHERs, E., Phys. Rev. B 14 (1976) 3185 and 3193.

[7] Gay, J. G., Smith, J. R. and Arlinghaus, F. J., Phys. Rev. Lett. 38 (1977) 561

[8] Abbati, I., Braicovich, L., Bertoni, G. M., Calandra, C. and Manghi, F., Phys. Rev. Lett. 40 (1978) 469.

[9] Wehking, F., BeckermanN, H. and Niedermayer, R. Surf. Sci. 71 (1978) 364 ;

Hermann, P., Niedermayer, H. and Roloff, H. F., Proc. 7th Intern. Vac. Congr. \& 3rd Int. Conf. Solid Surfaces (Vienna 1977) Vol. II, p. 2145 ;

Sass, J. K., Stucki, S. and Lewerenz, H. J., Surf. Sci. 68 (1977) 429.

[10] Le Lay, G., Quentel, G., Faurie, J. P. and Masson, A., Thin Solid Films 35 (1976) 273 and 289.

[11] Raether, H., Springer Tracts in Mod. Physics 38 (1965) 84.
[12] Boersch, H., Geiger, J., Hellwig, H. and Michel, H., Z. Phys. 169 (1962) 252.

[13] Daniels, J., Z. Phys. 203 (1967) 235.

[14] Otto, A. Petri, E., Solid State Commun. 20 (1976) 823.

[15] Observation with electron microscope of replicas of these $3 \mathrm{D}$ clusters, at $\theta \sim 10$, allow us to estimate their density $\left(\sim 5 \times 10^{7} / \mathrm{cm}^{2}\right)$ and their lateral dimension $(\sim 0.6 \mu)$. They cover only $20 \%$ of the whole surface and so the main part of the ELS signal comes from the first adsorbed layer. At $\theta \sim 30$, we find for these clusters nearly the same density and the same lateral dimension. Only their thickness has increased.

[16] Brillson, L. J., Phys. Rev. Lett. 38 (1977) 245.

[17] Brillson, L. J., Phys. Rev. Lett. 40 (1978) 260.

[18] HagemanN, H. J., Gudat, W. and KunZ, C., DESY SR-74/7 (1974).

[19] See the series of papers on band structures of $d$ band metals by SMith, N. V. et al., Phys. Rev. B 9 (1974) 1341-1376: Phys. Rev. B 10 (1974) 3197-3212; and recent photoemission data of ScheVdrik, N. J. and Liebowitz, D. Phys. Rev. B 16 (1977) 2395.

[20] RichtiE, R. H., Surf. Sci. 34 (1973) 1.

[21] E.vdriz, J. G. and SPICER, W. E., Phys. Rev. B 4 (1971) 41 Ht. 